\title{
Challenges to the Implementation of
}

\section{Interprofessional Education in Health Profession Education in Iran}

This article was published in the following Dove Press journal:

Advances in Medical Education and Practice

\author{
Soleiman Ahmady (D' \\ Zohrehsadat Mirmoghtadaie $\mathbb{I}^{2}$ \\ Davood Rasouli (D) ${ }^{3}$ \\ 'Department of Medical Education, \\ School of Medical Education, Shahid \\ Beheshti University of Medical Sciences, \\ Tehran, Iran; ${ }^{2}$ Department of \\ Virtualization in Medical Education, \\ Virtual School, Tehran University of \\ Medical Sciences, Tehran, Iran; ${ }^{3}$ School of \\ Medical Education, Shahid Beheshti \\ University of Medical Sciences, Tehran, \\ Iran
}

Background: Changes in the structure and nature of health care highlight the need for better collaboration between professions focusing on patient or health-care users. Interprofessional education (IPE) has attracted a lot of attention at the international level, and its positive consequences in different areas of health care have been investigated and approved. This study explored the opinions and viewpoints of professors and experts regarding the challenges to the implementation of interprofessional education in health profession education in Iran in 2018.

Methods: This qualitative study was conducted with 15 IPE professors and experts using semi-structured interviews. We used an inductive approach to content analysis as developed by Elo et al. The interviews were analyzed using Graneheim and Lundman method by MAXQDA software version 12

Results: The main challenges to the implementation of IPE were categorized into educational system, structural and cultural challenges. The educational challenges were the professors' lack of ability, a non-flexible and single-disciplined curriculum, and weaknesses in the current education. The professors and experts felt that the most important structural challenges included centralism, hierarchy of power, poor educational groundwork, and lack of support of organizations. Cultural challenges mainly related to the attitudes of managers, professors, and even students regarding IPE and the need for change.

Conclusion: Designing and implementing IPE in Iran face major challenges. Cultural and attitude issues were the greatest challenges to be addressed in the context of implementing IPE in health-care education.

Keywords: interprofessional education, multiprofessional education, shared learning, medical education

\section{Background}

As a modern, efficient and effective approach in improvement of the community health services quality and proportionate to the widespread global changes in the third millennium, Interprofessional education has attracted a lot of attention to the international level and its positive consequences in different areas of health care have been investigated and approved. ${ }^{1}$ Based on the definition of the World Health Organization, IPE "occurs when two or more professions learn from each other regarding the effective collaboration and improvement of health outcomes". 2 Through IPE, students and physicians can develop their competencies in the areas of knowledge, attitude, skills, and behaviors that enable them to participate in patient care, collaboratively. ${ }^{3}$
Correspondence: Davood Rasouli School of Medical Education, Shahid Beheshti University of Medical Sciences, Tehran, Iran

Tel +982I8670222

Email dr.rasouli24@gmail.com 
Changes in the structure and nature of care highlight the need for better collaboration between professions focusing on patient or health-care users which needs providing a more comprehensive, integrated, and patient-centered approach through the future health profession education. ${ }^{4,5}$ In their report about the achievements, challenges, and implications of the health system, the Iranian Ministry of Health identified a range of issues. These included asymmetric development in medical education, emphasis on specialization, a change in the pattern of diseases and lifestyle, lack of integration and the existence of island thinking and the lack of horizontal and vertical integration of curriculums. There was also inadequacy in intra-communication, inadequate inter-institutional interaction, lack of commitment within the education system to social responsibility and weakness of justice in meeting health-care needs. This report reflects the lack of attention to the team-based educational approaches to health education and the need to revise it. ${ }^{6,7}$ Along with changes in the health needs of communities over the past decades, the World Health Organization in 2010 warned against undesirable outcomes by emphasizing the lowered quality and safety provided by disqualified graduates in providing team care. ${ }^{8}$ There is no formal training courses for interprofessional education in Iran. Some universities understand the necessity of interprofessional education to improve patient care and hold their clinical education in the field of interprofessional with informal and unplanned manner. Few studies were conducted on IPE in Iran, and the major studies emphasize on the background, structure, facilitators, and barriers of this educational approach; ${ }^{9}$ however, a few qualitative studies investigated the perceptions of professors and students from the IPE. Mafinejad et al investigated the perception and perspective of faculty members and students about IPE in an integrated system for IPE planning and implementation. Their results were classified into four categories, namely, educational structure, professional identity, moderating factors, and perceiving concepts. ${ }^{10}$ The Irajpour et al, study results indicated that although IPE in Iran had a significant expansion, it was unofficially. ${ }^{11}$ The aim of this study was collecting and analyzing the views, experiences, and perspectives of the people involved in IPE in Iran's educational system to identify the important challenges of IPE.

\section{Methods}

\section{Ethics}

To comply with ethical considerations and protect the participants rights. Ethics approval was obtained from the
Shahid Beheshti University of medical sciences and then researcher introduced himself to the participants, explained the goals of the research, and obtained informed consent. Participants took part in the study, voluntarily. After the completion of the analysis and publication of the article, interviews were deleted.

\section{Research Design}

This study was conducted using qualitative content analysis, aiming at providing new cognitions, promoting the researcher's perception of the phenomena and identification of operational strategies. ${ }^{12}$ This study aims at explaining and describing the experiences and views of IPE experts in the Iranian educational system to identify the important challenges of IPE.

\section{Participants}

The participants were comprised of professors and experts in the field of IPE. To conduct the research, 15 faculty members in this area were selected based on the purposive sampling and in-person semi-structured interviews ${ }^{13}$ were conducted during May-August 2018. Using snowball method, more participants took part in the present study until the data saturation was achieved. The interviewer was a Ph.D. student of medical education whom the participants were not familiar with. The maximum variation was observed in participant's selection. Since basically the number of participants in qualitative studies is not determined, sampling was continued until data saturation was achieved, so that by conducting the interview, no more themes, dimensions, components, or identity were extracted from the participants, ie, the final interviews only confirmed or proved the previous findings. Considering that there are no official IPE courses in the Iranian medical education system and students or patients are not familiar with this approach, only the professors involved in this field were sampled.

\section{Data Collection}

In order to collect the data, semi-structured interviews were used. In order to conduct the interview, informed consent was obtained after contact with participants. The time and place of the interview were selected according to the participants. To prepare the participants for interview, the general framework of the topics was expressed. After time coordinating, the semi-structured interviews began with informed consent and a brief explanation of the research and objectives. Interviews were begun with open and public questions and then led to enlightening 
and in-depth questions. During the interview and based on the respondents' answers, open and probing questions were posed to clarify the details. The interview time varied from 39 to 72 mins, with an average of approximately 56 mins, based on the willingness and readiness of the participants, recorded by a digital recording device. Although the main data were taken from semi-structured interviews, observations, and observation notes, field notes and memory notes were also used alongside the data. Observation notes illustrate what happened during the interview. The field notes are a report of interactions observed in the field and show analytical insights during the data collection. The memory notes also express deep thoughts about the event, written often after leaving the field and analyzing the data. ${ }^{14}$ Although these data were not all added to the data collected from the interviews, it helped to manage, pose further questions and better understanding the relationship between the topics, thus directed the collection and analyzed the data.

\section{Data Analysis}

The data analysis process was conducted according to the proposed steps of Graneheim and Lundman where the researcher transcribed the interviews and studied those several times in order to obtain a complete knowledge of them. ${ }^{15}$ After each interview, the audio file was carefully transcribed and the text of the interviews was read several times for data analysis. Transcripts returned to participants for comment and correction. Meaning units were determined and condensed with a description close to the text. Then, a list of codes was prepared and with revising, semantic review, determining the similarities and differences in meaning, the similar codes were placed through reduction and induction method at a more abstract level. By continuous comparison, the acceptable sub-categories and categories were obtained. All interviews and observations were considered as the analysis unit. Paragraphs, sentences, or words were considered as meaning units. Subsequently, the meaning units were named through codes and reached the level of abstraction and conceptualization according to their latent meaning. The codes were compared with each other in terms of similarities and differences, and were categorized under abstract categories with a specific label. Eventually, by comparing the categories with each other and thorough and deep reflection on them, the latent content of the data was introduced as the theme of the study. All interviews were independently analyzed by the two researchers. MAXQDA v.12 software was used to facilitate the forward and backward, listing, categorization, frequent comparison of various data and retrieval of quotes in the data analysis process.

The proposed criteria for Guba and Lincoln were used for the trustworthiness of the study. ${ }^{16}$ To ensure the findings, the author gave further validity to the data by spending adequate time collecting and reviewing data, using variety in sampling (selecting participants with different characteristics), giving interview feedback to participants, and confirming the categories derived from the interview texts. In order to achieve trustworthiness, we used the findings dependency; so that in order to analyze and revise the transcribed interviews, they were presented to the faculty members familiar with the qualitative research to ensure the dependency of the content and the results. Transferability was assigned to readers under similar conditions. The resulting categories of the quotes of the participants were presented as said before. Since the interviewers were the data collection instrument, this research is not as error-free as other qualitative research, because the mentalities, thoughts, and opinions of the interviewer sometimes affect the subject of research and the process of data collection. Attempts were made to bracket the researcher's thoughts through the process of collecting and analyzing data to conduct a proper research. In addition, all participants were assured that their responses remained confidential to the researcher to reduce the probable bias of the respondents.

\section{Results}

Fifteen professors participated in the study which eventually 15 interviews were conducted. The participants fields included medicine $(\mathrm{N}=4)$, nursing $(\mathrm{N}=6)$ and medical education $(\mathrm{N}=5)$. Ten participants were Faculty member and 5 participants were Manager.

Participants argued that the development and implementation of IPE in the field of medical education in the country faces many challenges that have to be overcome. According to the participants' perspective, these challenges fell into three categories: educational, structural, and cultural challenges (Table 1).

\section{Educational Challenges of IPE}

Participants argued that one of the main challenges facing IPE in the country is challenges pertaining to education. Approximately all participants stated that the lack of ability of professors was one of the major educational 
Table I Codes, Subcategories and Categories of Study

\begin{tabular}{|c|c|c|}
\hline Codes & Sub Categories & Categories \\
\hline $\begin{array}{l}\text { Lack of familiarity of professors } \\
\text { with IPE }\end{array}$ & \multirow[t]{5}{*}{$\begin{array}{l}\text { Lack of ability of } \\
\text { professors }\end{array}$} & \multirow[t]{28}{*}{$\begin{array}{l}\text { Educational } \\
\text { challenges }\end{array}$} \\
\hline $\begin{array}{l}\text { Pseudo-IPE knowledge of } \\
\text { professors }\end{array}$ & & \\
\hline $\begin{array}{l}\text { Wrong Belief of professors in } \\
\text { knowing IPE }\end{array}$ & & \\
\hline Lack of skill of professors in IPE & & \\
\hline Lack of knowledge of professors & & \\
\hline Great distance from IPE & \multirow{12}{*}{$\begin{array}{l}\text { Weakness in } \\
\text { current education }\end{array}$} & \\
\hline Informal interpersonal Education & & \\
\hline Unplanned IPE & & \\
\hline Traditional education system & & \\
\hline Single professional education & & \\
\hline $\begin{array}{l}\text { Disproportionate education with } \\
\text { teamwork }\end{array}$ & & \\
\hline Person-centered education & & \\
\hline Teacher based education & & \\
\hline Inefficient education & & \\
\hline Old teaching methods & & \\
\hline $\begin{array}{l}\text { Lethargy-inducing educational } \\
\text { environments }\end{array}$ & & \\
\hline Stressful education & & \\
\hline Traditional thinking & \multirow{5}{*}{$\begin{array}{l}\text { Lack of innovation } \\
\text { and creativity }\end{array}$} & \\
\hline Lack of creativity in the education & & \\
\hline Restrictive environments & & \\
\hline Passive students & & \\
\hline Not worthy of new ideas & & \\
\hline Single professional curriculum & \multirow{6}{*}{$\begin{array}{l}\text { Non-flexible } \\
\text { curriculums }\end{array}$} & \\
\hline Subject-centered curriculum & & \\
\hline The need to modify the curriculum & & \\
\hline Rigid curriculum & & \\
\hline Traditional curriculum & & \\
\hline Inability to change curriculum & & \\
\hline Lack of decentralization & \multirow[t]{2}{*}{$\begin{array}{l}\text { Centralization and } \\
\text { hierarchy of power }\end{array}$} & \multirow{2}{*}{$\begin{array}{l}\text { Structural } \\
\text { challenges }\end{array}$} \\
\hline Pyramid Decision Making & & \\
\hline
\end{tabular}

(Continued)
Table I (Continued).

\begin{tabular}{|c|c|c|}
\hline Codes & Sub Categories & Categories \\
\hline \multicolumn{3}{|l|}{ Top-down decision-making } \\
\hline \multicolumn{3}{|l|}{ Power hierarchy } \\
\hline \multicolumn{3}{|l|}{ Concentration of power } \\
\hline \multicolumn{3}{|l|}{ Inappropriate power distribution } \\
\hline \multicolumn{3}{|l|}{ Power levels } \\
\hline Inappropriate structures & \multirow[t]{7}{*}{$\begin{array}{l}\text { Inadequate } \\
\text { infrastructures }\end{array}$} & \\
\hline Limited space & & \\
\hline Traditional infrastructure & & \\
\hline Separate schools & & \\
\hline Vital roles of Infrastructure & & \\
\hline Necessary infrastructure & & \\
\hline \multicolumn{2}{|l|}{ Structural Problems } & \\
\hline Organizational Inhibition & \multirow[t]{5}{*}{$\begin{array}{l}\text { Lack of } \\
\text { organizational } \\
\text { support }\end{array}$} & \\
\hline $\begin{array}{l}\text { Necessary organizational } \\
\text { facilitation }\end{array}$ & & \\
\hline Complex administrative system & & \\
\hline Resistance in organizations & & \\
\hline \multicolumn{2}{|l|}{ Cumbersome regulations } & \\
\hline Resistance at high levels & \multirow[t]{7}{*}{$\begin{array}{l}\text { Resistance to } \\
\text { change }\end{array}$} & \multirow[t]{13}{*}{$\begin{array}{l}\text { Cultural } \\
\text { challenges }\end{array}$} \\
\hline Resilient Attitudes of Managers & & \\
\hline Mental resistance & & \\
\hline Rapid rejection of Directors & & \\
\hline Resistance at managerial levels & & \\
\hline Resistance in universities & & \\
\hline Strong resistance & & \\
\hline The traditional attitude & \multirow[t]{6}{*}{$\begin{array}{l}\text { Non-commitment } \\
\text { of faculty members }\end{array}$} & \\
\hline Lack of enthusiasm to IPE & & \\
\hline A single professional attitude & & \\
\hline $\begin{array}{l}\text { Negative attitude to other } \\
\text { professions }\end{array}$ & & \\
\hline $\begin{array}{l}\text { Misconceptions about other } \\
\text { professions }\end{array}$ & & \\
\hline Negative attitude to IPE & & \\
\hline
\end{tabular}

(Continued) 
Table I (Continued).

\begin{tabular}{|l|l|l|}
\hline Codes & Sub Categories & Categories \\
\hline $\begin{array}{l}\text { Not commitment to other } \\
\text { professions learning }\end{array}$ & & \\
\cline { 1 - 2 } Self-confidence & Destructive & \\
\cline { 1 - 2 } Suspicion & & \\
\cline { 1 - 2 } Hatred & & \\
\cline { 1 - 2 } Top-down view & & \\
\cline { 1 - 2 } Conflict & & \\
\cline { 1 - 3 } Self-lsolation & & \\
\hline
\end{tabular}

challenges. One of the problems with IPE based on the experiences of professors was the false belief of familiarity with IPE. Even the specialized boards are not familiar with IPE:

Everyone thinks they know, though when you ask them in practice, they know nothing. We changed environments for implementing IPE at the University of Tehran, where nobody heard or knew nothing about IPE.

The professors were unfamiliar with the IPE. Not only faculty members knew little about new educational approaches, but also specialist boards did not know about these approaches.

Since most of the professors in the field of health professional education were not fully familiar with this approach or sporadically gained information in this regard; thus, the current unofficial courses for IPE were inefficient:

We have not planned Interprofessional education, but some universities might have been compensated this defect in some ways or some sections. In general, although, we have not designed Interprofessional education, this might happen in practice.

Professors in the field of health professional education, especially the highly experienced, preferred to use traditional and familiar approaches to education due to lack of familiarity with new educational approaches. IPE in Iran is considered as a new approach to the preparation of health professional students. Therefore, faculty members of the medical sciences have difficulty using this approach and do not use it as far as possible. Therefore, the lack of innovation and excessive adherence to the traditional education system is one of the challenges facing IPE:
We do not seek innovation in our education and prefer the traditional and existing education. Each of the disciplines doesn't get involved with other disciplines. Students are basically educated with an individual approach since the beginning.

According to professors, rigid, non-flexible, and singledisciplined curriculums are one of the most important educational challenges facing IPE. The health profession curriculum in Iran is based on the subject of the course and no position is considered for IPE:

The present curriculum is unsuitable for the integration of IPE. If the curriculum is taken into consideration, then the commonalities should be taken into consideration and should be supplemented or appended to the current curriculum. Different courses should be injected into the curriculum for various educational environments.

The professors agree that the curriculum should be interprofessionally written and investigated in order to identify and consider the opportunities available for IPE:

The interprofessional curriculum should be written and investigated interprofessionally. In the existing curriculum, the points that can be interprofessionally implemented should be determined, and interprofessionally conducted in those particular points. In the existing curriculum, the interprofessional opportunities can be identified and reviewed, but they cannot be interprofessional in essence, because they are written as a single discipline.

\section{Structural Challenges of Interprofessional Education}

In the perspective of participants, appropriate structures were one of the most important factors affecting the IPE design and implementation. Participants in the study stated some obstacles such as centralism, power hierarchy, and inadequate educational environments to implementing these programs.

Our universities are struggling with problems such as centralism, levels of power, and unique structure where IPE can be raised as a solution, the hierarchy of power must be eliminated, and students should see each other in the same level. It is very difficult to implement such educations in the hierarchical fields of Iran.

According to participants, creating or improving the existing platforms is the first step in implementing IPE: 
Laying the groundwork is the first pillar of everything. Now, in education, which is one of the most important pillars of the country's progress, we cannot do a useful work without the proper groundwork, and in my opinion, in the first step, we should provide the appropriate groundwork for this particular type of education.

In hospitals, clinical education is similar to island, and a variety of disciplines, including medicine, nursing, pharmacy, midwifery, physiotherapy, radiology, social working, laboratory, and occupational therapy are educated in separate environments, with a variety of methods there is little interaction between students and faculty members. One of the faculty members stated:

One of the problems that prevent the design and implementation of IPE is the structural problems that exist in our education system. The existing structures should be changed for IPE. In our environment, these things are impossible, because they are not attractive.

Policymakers and educational managers have not yet understood the need to use IPE as a useful approach in solving health profession problems after completing their education, despite their concerns about health profession education and work and searching for new educational methods. IPE would be difficult and almost not implementable without the support of various organizations involved in education:

The support of various organizations is vital for the IPE implementation. While ago there were talks about community-oriented education of students from different disciplines in rural areas, where a nursing student, a medical student, and even in some provinces, a pharmacy student stayed, I mean in the social medicine rotation, The kids worked practically for a month as a resident, but they were canceled because of issues like cost and security, and a couple of other things. It was precisely a targeted IPE.

Currently, almost all of the colleges of medical sciences in the country are educating students separate from each other and have little interaction in the shared fields of education because of their distance as well as inappropriate physical space. Participants acknowledged that appropriate educational environments should be developed for designing and developing IPE initiatives and projects in the country's education system:

IPE cannot be translated within the existing contexts and environments, and a new field should be created that is patient-centered. In many cases, educational environments can be improved without having to pay any certain costs.
For example, in the delivery room with both the midwifery students and residents, we need to change the environment so that they both learn from each other.

Obviously, as long as people are physically distant, they lack sufficient opportunities to interact and get familiar, and thus will have trouble cooperating. Regarding the need for interaction and cooperation in the IPE, participants in the study also acknowledged the following:

As long as our faculties are separated from each other, even the professors do not meet each other except for few sessions, so expecting cooperation on behalf of students would be in vain. The wall between the faculties should be removed. First, we need to physically connect students and professors, certainly, over time, students will somehow work together

\section{Cultural Challenges of Interprofessional Education}

The inappropriate cultural environment creates an inappropriate learning environment for IPE. This inappropriate cultural environment exists for IPE at all levels, including curriculum directors and planners, faculty members and even students. In order to overcome this inappropriate cultural environment of universities, the educational officials of different professions should have more interaction with each other. This problem is seen not only at universities but also in clinical settings. The professors stated that considering IPE in the country, there are attitudinal problems:

Basically, our problems are mostly related to attitude. Because our look is either all or nothing, we usually find these attitudinal problems. In my opinion, the attitude dimension of education has not gone well in other dimensions. In many universities, there is now a tendency towards putting together the students with the same field.

IPE requires more attitude intervention than technical intervention. It is necessary to work on the attitude of people before the implementation of curriculum, because all competencies must take place within the cultural context of the country.

Because of resistance against shift to IPE in managers, changing the attitudes is one of the requirements of moving toward IPE and break this resistance. 
Many university and institute managers are reluctant to conduct such educations due to problems such as financing, executive issues, and the resistance of the professors.

The importance of the problem of the structures and the educational environment for IPE is far less than the problem with the managers' mentality and the minds of the people prevent the implementation of such education.

One of the pillars of interprofessional education is that, in addition to the lack of readiness for knowledge, they lack readiness considering attitudes to implement IPE. Successful IPE requires enthusiasm, commitment, and positive attitudes towards the other disciplines, individuals, and teamwork.

An interprofessional professor with a positive look at the rest of the professions can contribute with these opportunities. In clinical care services, care is provided as a team, but, the problem is that the members of the group often do not know about being a group or do not recognize themselves and do not consider that this group should cooperate intentionally, consciously and in a programmed manner.

We have to work on people's attitudes in order to learn to respect each other. Respecting others and accepting the opinions of others is a kind of valuation. Everything that is respected is increasingly becoming valuable.

The misleading and destructive attitudes in the society and the university create negative stereotypes among students and prevent students from knowing about other disciplines and individuals. In many cases, students of other disciplines consider themselves higher than other disciplines and are reluctant to cooperate and interact where their destructive effects on the health system are revealed after graduation.

Students of different disciplines lack a good attitude towards each other, which provokes hatred. When people are employed, they show a series of strange behaviors. Bad attitudes and suspicions are found among different people. If they were normally educated since the beginning, while knowing all the limitations of each other, they will respect and realistically accept each other.

The culture we have in our universities has made our medical students to have a higher and different opinion of themselves. These attitudes prevents interaction among students, so students have no common mental model for the patient. IPE itself is a solution to this problem.

\section{Discussion}

According to the participants, designing and planning of IPE in the educational system of the country are associated with educational, structural, and cultural challenges.

\section{Lack of Ability of Professors}

One of the main challenges of IPE was the lack of ability of the professors. Developing the faculty members is recognized as a key factor in the success of IPE projects. ${ }^{17}$ Lawlis et al stated that a lack of individual skill and commitment at the college level is a barrier to IPE. ${ }^{18}$ University professors and clinics need to prepare for IPE, especially for the facilitating role. ${ }^{19}$ Increasing collaborative activities at different faculties increases the awareness and interest of faculty members from IPE, although many institutional and individual barriers may prevent their full involvement as IPE leaders. $^{20}$ Introducing and clarifying the benefits of IPE is a strategy in raising awareness. ${ }^{21}$

\section{Non-Flexible Curriculum}

The non-flexible and traditional curriculum was identified as another challenge for IPE. Nowadays, in almost all Iranian universities, students of different health professions are educated in separate classes or in clinical settings without the opportunity to interact and share information, recognize the role and perceive the differences, commonalities and abilities, responsibilities, and a shared goal, which is the ground for providing teamwork. ${ }^{22-25}$ In Canada, the main obstacles to the IPE timetable were the dry curriculum and a defect in the perceived value of IPE. $^{26}$

\section{Weakness in Current Education}

Dependence on traditional, theme-based, singledisciplined, and isolated educational approaches is another important challenge for IPE. Education in isolated conditions creates worldview, language, culture and attitude specific to each profession, the appearance of prejudices, patterns and specific mental forms, territoriality and extremist tribalism, negative competitions, imbalance of power and superiority seeking. ${ }^{19,27-29}$ Bridges states that the most important adverse effect of isolated and separate education of health professions includes the disruption and failure in the process of professionalization and socialization of students and consequently unfavorable professional behaviors, ie, non-professional behaviors in graduates after entering the work environment. ${ }^{30}$ 
Based on the study, centralism, hierarchy of power, poor educational groundwork, and lack of support were the structural challenges of IPE.

\section{Centralism and Hierarchy of Power}

According to a study by Olenick et al, the existence of hierarchy, existing program constructs, conventions, the construct of the current health services, public perceptions, the current practice domain, financing, and planning were the challenges and barriers to IPE transmission. ${ }^{31}$ Power distribution is one of the most challenging discussions in IPE. $^{21}$

\section{Lack of Organizational Support}

Executive-level barriers mainly include an understanding of whether IPE worth direct investment and the change of institution's mission. It is important for managers to understand the need for change in profession education and practice as changes in health care and facilitate it. Political support (government) for interprofessional education can help create the "motivation" for educational institutions to begin the Interprofessional operation. ${ }^{32}$ In the literature, there is a consensus that the success of any interprofessional project depends on attracting the commitment of institutional and political leadership. At the level of academic institutions, it is mentioned that the support of senior managers with the decision-making power in educational policies and resource control is needed. Gaining support from the key senior managers can be a challenge, but IPE can become a priority issue with their support. ${ }^{33}$ Faculty members also need to understand the benefits of IPE have full involvement. Faculty members may resist due to increased workload and shortage of time. IPE managers are responsible to motivate faculty members to make IPE changes and developments.

\section{Inadequate Infrastructures}

The operational management of the educational system in many professions requires a change in the curriculum arrangement, including the physical space as well as designing the course and timetable. Designing and implementing IPE is a structural task that faces challenges such as course scheduling, course content alignment, resistance of faculty members and managers, and a culture of valuing the collaborative learning among faculty members and students, and institution policies to share courses among faculties. $^{34}$

\section{Destructive Attitudes and Resistance to Change}

Based on the findings, the cultural challenges arising mainly due to the attitudes of managers, professors, and students affect the IPE design and implementation. Barret et al argued that attitudinal differences in health profession, faculty members and students, such as lack of resources and commitment could negatively affect the IPE implementation. ${ }^{35}$ Developing a culture for IPE requires the professors from different disciplines that value IPE and are encouraged to work collaboratively to create a shared perspective and shared objectives. Inappropriate culture environment in universities and hospitals, especially in educational hospitals, creates an inappropriate learning environment for IPE. Therefore, in most educational programs, an inappropriate professional and individualized culture is encouraged. Such inappropriate culture for IPE originates by authorities from curriculum developers and designers to faculty members in this process. ${ }^{32}$

\section{Non-Commitment of Faculty Members}

Professors need to engage in acquiring skills, improving quality, patient safety, and interdisciplinary interactions within the health-care system to teach content and serve as role model and mentors for students. ${ }^{34}$ In addition to the role of beliefs and values in the essence of interprofessional education, attitudes continue to be noticed as an ideological element. Significant emphasis of almost all participants highlights the importance and necessity of cultural change, the role of attitudes and ideological elements in IPE. The process of changing attitudes and moving towards interprofessional education requires a change in the organization's culture and commitments of faculty members which is a slow and gradual process. ${ }^{21}$

\section{Conclusion}

Considering the ever-increasing complexity of needs and health-care services, the importance of teamwork and participation in the provision of more health-care services becomes evident. Medical science education is inevitably required to use IPE to gain teamwork skills and effective care. Interprofessional education as a new educational approach focuses on Interprofessional interaction in the education and learning process, and the promotion of the socialization process of medical science students leads to the acquisition of identity and professional role, competency, 
and capability to develop effective interactions and extensive collaboration between professionals and the provision of comprehensive, integrated team-based patient care. Educational policymakers in Iran should understand the importance of IPE and address the barriers and challenges they face. IPE challenges take place at policy-making, management, faculty members, and student levels. Evidencebased policies, the establishment of IPE centers at the Ministry of Health and Universities of Iran, budget allocations, the design of IPE courses for managers, professors, and students, and the development of IPE curriculums are necessary for IPE development. One of the important ways to start IPE in Iran is to design and implement small curses of IPE in the universities that can be researched in the future.

\section{Ethics and Consent Statement}

Ethics approval was obtained from the Shahid Beheshti University of medical sciences. Written informed consents were obtained from all participants.

\section{Acknowledgment}

We sincerely thank all faculty members from medical universities of Iran who participated in this study.

\section{Author Contributions}

All authors contributed to data analysis, drafting or revising the article, gave final approval of the version to be published, and agree to be accountable for all aspects of the work.

\section{Disclosure}

The authors declare that they have no competing interests.

\section{References}

1. Reeves S, Zwarenstein M, Goldman J, et al. The effectiveness of interprofessional education: key findings from a new systematic review. $J$ Interprof Care. 2010;24(3):230-241. doi:10.3109/ 13561820903163405

2. Yan J, Gilbert J, Hoffman S, Rodger S, Ishikawa Y. WHO Study Group on Interprofessional Education and Collaborative Practice. J Interprof Care. 2007;21(6):587-589.

3. Lesley Bainbridge P, Louise Nasmith M, Wood V. Competencies for interprofessional collaboration. J Phys Ther Educ. 2010;24(1):6. doi:10.1097/00001416-201010000-00003

4. Department of Health. National Service Frameworks for Mental Health: Modern Standards and Service Models. London: DoH; 1999a.

5. Department of Health. He NHS Plan. London: DoH; 2001b.

6. Vafadar Z, Vanaki Z, Ebadi A. Barriers to implementation of team care and interprofessional education: the viewpoints of educational managers of iranian health system. Iran J Med Educ. 2015;14 (11):943-956.
7. Ministry of Health and Medical Education. Achievements, challenges and horizons of the Islamic Republic of Iran Health System; 2015.

8. World Health Organization. Framework for Action on Interprofessional Education and Collaborative Practice; 2010.

9. Yamani N, Asgarimoqadam M, Haghani F, Alavijeh AQ. The effect of interprofessional education on interprofessional performance and diabetes care knowledge of health care teams at the level one of health service providing. Adv Biomed Res. 2014;3. doi:10.4103/22779175.140622

10. Mafinejad MK, Ahmady S, Arabshahi SKS, Bigdeli S. Interprofessional education in the integrated medical education and health care system: a content analysis. J Adv Med Educ Prof. 2016;4 (3): 103.

11. Irajpour A, Barr H, Abedi H, Salehi S, Changiz T. Shared learning in medical science education in the Islamic Republic of Iran: an investigation. J Interprof Care. 2010;24(2):139-149. doi:10.3109/ 13561820902886246

12. Sandelowski M. Whatever happened to qualitative description? Res Nurs Health. 2000;23(4):334-340. doi:10.1002/(ISSN)1098-240X

13. Higginbottom GMA. Sampling issues in qualitative research. Nurs Res. 2004;12(1):7.

14. Corbin J, Strauss A, Strauss AL. Basics of Qualitative Research. Sage; 2014.

15. Graneheim UH, Lundman B. Qualitative content analysis in nursing research: concepts, procedures and measures to achieve trustworthiness. Nurse Educ Today. 2004;24(2):105-112. doi:10.1016/j.nedt.2003.10.001

16. Patton MQ. Qualitative Research and Evaluation Methods. Thousand Oaks, CA: Sage Publications; 2002.

17. Ho K, Jarvis-Selinger S, Borduas F, et al. Making interprofessional education work: the strategic roles of the academy. Acad Med. 2008;83(10):934-940. doi:10.1097/ACM.0b013e3181850a75

18. Lawlis TR, Anson J, Greenfield D. Barriers and enablers that influence sustainable interprofessional education: a literature review. J Interprof Care. 2014;28(4):305-310. doi:10.3109/13561820.2014.895977

19. Barr H. Interprofessional Education: Yesterday, Today and Tomorrow London. England Learning and Support Network, Centre for Health SCience and Practice; 2002.

20. Hall LW, Zierler BK. Interprofessional education and practice guide no. 1: developing faculty to effectively facilitate interprofessional education. J Interprof Care. 2015;29(1):3-7. doi:10.3109/135618 20.2014.937483

21. Irajpour AAH, Barr H, Salehi SH, Changiz T. Development of Shared Learning in Medical Sciences Education in Islamic Republic of Iran. Isfahan University of Medical Sciences; April 2009.

22. Elisabeth C, Ewa P, Christine W-H. The team builder: the role of nurses facilitating interprofessional student teams at a Swedish clinical training ward. Nurse Educ Pract. 2011;11(5):309-313. doi:10.1016/j.nepr.2011.02.002

23. Flexner GJA. The roots of interprofessional education. J Contin Educ Health Prof. 2008;28(Suppl 1):S11-S4. doi:10.1002/chp.201

24. Lapkin S, Levett-Jones T, Gilligan C. A systematic review of the effectiveness of interprofessional education in health professional programs. Nurse Educ Today. 2013;33(2):90-102. doi:10.1016/j. nedt.2011.11.006

25. Margalit R, Thompson S, Visovsky C, et al. From professional silos to interprofessional education: campuswide focus on quality of care. Qual Manag Health Care. 2009;18(3):165-173. doi:10.1097/ QMH.0b013e3181aea20d

26. Buring SM, Bhushan A, Broeseker A, et al. Interprofessional education: definitions, student competencies, and guidelines for implementation. Am J Pharm Educ. 2009;73(4):59. doi:10.5688/ aj730459

27. Baker L, Egan-Lee E, Martimianakis MA, Reeves S. Relationships of power: implications for interprofessional education. J Interprof Care. 2011;25(2):98-104. doi:10.3109/13561820.2010.505350 
28. Hall P. Interprofessional teamwork: professional cultures as barriers. $J$ Interprof Care. 2005;19(sup1):188-196. doi:10.1080/1356182050 0081745

29. Hean S, Dickinson C. The contact hypothesis: an exploration of its further potential in interprofessional education. J Interprof Care. 2005;19(5):480-491. doi:10.1080/13561820500215202

30. Bainbridge L, Nasmith L, Orchard C, Wood V. Competencies for interprofessional collaboration. J Phys Ther Educ. 2010;24(1):6-11. doi:10.1097/00001416-201010000-00003

31. Olenick M, Allen LR, Smego RA Jr. Interprofessional education: a concept analysis. Adv Med Educ Pract. 2010;1:75.

32. Mafinejad MK, Ahmady S, Arabshahi SKS, Bigdeli S. Effective factors in the design and implementation of the interprofessional education from the faculty members' perspective: A qualitative study. Res Dev. 2013;2(1):25-30.
33. Oandasan I, Reeves S. Key elements of interprofessional education. Part 2: factors, processes and outcomes. J Interprof Care. 2005;19 (sup1):39-48. doi:10.1080/13561820500081703

34. Barnsteiner JH, Disch JM, Hall L, Mayer D, Moore SM. Promoting interprofessional education. Nurs Outlook. 2007;55(3):144-150. doi:10.1016/j.outlook.2007.03.003

35. Barrett G, Greenwood R, Ross K. Integrating interprofessional education into 10 health and social care programmes. J Interprof Care. 2003;17(3):293-301. doi:10.1080/1356182031000122915

\section{Publish your work in this journal}

Advances in Medical Education and Practice is an international, peerreviewed, open access journal that aims to present and publish research on Medical Education covering medical, dental, nursing and allied health care professional education. The journal covers undergraduate education, postgraduate training and continuing medical education including emerging trends and innovative models linking education, research, and health care services. The manuscript management system is completely online and includes a very quick and fair peer-review system. Visit http://www.dovepress.com/testimonials.php to read real quotes from published authors. 